\title{
Food for Thought: The Socioeconomic Impact of Child Malnutrition and Maternal Health on the Academic Performance of Filipino School Children
}

\author{
Vashti Alexandra H. Dominguez ${ }^{1}$, Bernadette Louise B. Halili
}

\begin{abstract}
The study intends to investigate the effects of child malnutrition and maternal health on academic performance of Filipino school children. Previous research has shown correlation while no studies have proven causality, and so the study aims to fill the gap. Academic performance is defined as educational attainment and cognitive development. For health variables, child malnutrition is represented by prevalence of wasting in children under age 5 and maternal health is demonstrated as the percentage of pregnant women receiving prenatal care. Income, as annual GDP growth, and government expenditure on health and on education are also examined as economic variables. A multiple linear regression estimation model, based mainly on Christopher Ruhm's economic model on child outcomes, showed that maternal health had a significant impact on cognitive development while malnutrition was significant to educational attainment, whereas the most significant economic variable was government expenditure on education. The researchers therefore recommended a focus on government policy with respect to accessible prenatal care for mothers and proper nutrition for children.
\end{abstract}

Keywords: health economics, development economics, child malnutrition, maternal health, academic performance, cognitive development, educational attainment, wasting, prenatal care

\section{Introduction}

The World Bank has stated in Repositioning Nutrition as Central to Development, that the effects of malnutrition in children are what contribute to slow economic growth and the perpetuation of poverty, therefore fortifying the relevance of this particular health variable to the study. In the case of developing countries such as the Philippines, malnutrition comes in the form of being underweight or stunted and is caused mainly by the undernutrition as well as vitamin and micronutrient deficiencies.

In a previous study, Glewwe and King (2001) focused on determining whether poor nutrition causes poor school performance among children, given that the other studies have only shown a correlation. The article concludes that the various forms of the model did not support neither the claim that the most critical period is the first six months of life nor the hypothesis that prenatal nutrition is more critical than postnatal nutrition. However, it did find that "stunting at age 2 for instance has adverse negative effects on schooling".

According to an impact evaluation of the School-Based Feeding Program of the Department of Education in the Philippines, as conducted by PIDS, the program produced positive results. However, the limitations of the SBFP seem to be just as vast as the scope achieved.

\footnotetext{
$\left.\right|^{1}$ Department of Economics, Ateneo de Manila University. Manila, Philippines.

$\left.\right|^{2}$ Graduate student in Universidad del Pais Vasco, Bilbao, Spain.
} 
A study has also shown that malnutrition in children is also caused by the quality of the nutrition status of mothers. According to Sizing Up: The Stunting and Child Malnutrition Problem in the Philippines, "the first 1,000 days, or from conception through the first two years of life, are recognized as critical window of opportunity for growth and human development [...] thus, missing out on this period in terms of providing adequate nutrition to mother and the child will have irreversible effects later on".

The World Bank suggests that the most important limiting factors that affect undernutrition in a country are "inadequate knowledge about the benefits of exclusive breastfeeding and complementary feeding practices and the role of micronutrients and [second,] the lack of time women have available for appropriate infant care practices and their own care during pregnancy."

Stewart et al. (1996) study called Issues in Measuring Maternal Morbidity: Lessons from the Philippines Safe Motherhood Survey Project suggests that in order to improve the status of women's health in the Philippines, service-related issues on specific health problems must be explored further.

Meanwhile, in Maternal and Child Undernutrition: Consequences for Adult Health and Human Capital, Victora et al. (2008) finds that undernourished women tend to become shorter adults thus, produce smaller children. The observed trend in related literature reveals that there is an existing positive relationship between birth weight and cognitive development. With regards to attained schooling, the analysis showed undernutrition indicators to be associated with lower educational achievements.

In the regression study of Victoria et al., it is observed that height-for-age and weightfor-age play a significant factor in the relationship between stunting and school performance. Long-term effects of maternal and child undernutrition is also mentioned to last as far as three generations. According to the study, economic agendas must include reduction in malnutrition through investments and policy changes in maternal health, for there to be improvements in the physical and human capital.

In Who Provides Good Quality Prenatal Care in the Philippines?, which was conducted by the PIDS. Lavado et al, it was discussed that while prenatal coverage is available, both morbidity and mortality related to pregnancy are still high in the country.

Unsurprisingly, stunting is prevalent in developing nations. Sen and Begum (2009) suggest that regardless of socioeconomic level, a mother's health status significantly determines a child's overall health condition.

The researchers also examined the link between women's agency and child wellbeing. Women who are better educated are more exposed to maternal and childcare practices. In terms of women's agency, higher education gives way for more opportunities to improve a woman's position and household condition. In conclusion, women's agency affects child nutrition both directly and indirectly.

Jefferis et al. (2002) studied the combined effect of social class and birth weight on cognitive trajectories during their education. Their study concluded that birth weight and social class have independent effects on cognitive development, but the novel finding is that social class at birth describes more of the variation in scores.

A study done by Alderman et al. (2001) concluded that both at micro and macro levels, "sustained income growth can achieve a sizable reduction in malnutrition in the next two decades". 
The main research gap that has been observed pertains to the relatively limited scope that has thus been reached in this field, insofar as only correlation and not causality has been shown by previous studies. Additionally, data used in these studies are already outdated.

While the literature focused primarily on non-income aspects, several other factors that are socioeconomic in nature and closely related to this study have also been duly recognized in previous studies.

As seen in the studies examined, informational asymmetries linked to the chosen health variables must therefore be solved through government intervention.

\section{Results}

A combination of two theoretical frameworks will be used. First is Michael Grossman's demand for health model that illustrates the treatment of health as an outcome of investment. The second is Gary Becker's household production model that puts emphasis on the role of non-market time in household production. Both will be used to better represent the relationships of the variables at hand. Both frameworks greatly influenced Christopher Ruhm's economic model.

A multiple linear regression model will be used as the study's initial estimation model, in consideration of the empirical model such that:

$\boldsymbol{A C P}=\beta 0-\beta 1 W E I G H T+\beta 2 P R E N A T A L+\beta 3 G D P+\beta 4 E X P+u(1)$

In this specification, ACP represents the academic performance of school children in the Philippines, WEIGHT represents child malnutrition, PRENATAL is for maternal health, GDP represents income, and EXP is for the per capita government expenditure on health, while the variable $u$ represents the error term, where all factors related to it are uncorrelated with the explanatory variables. In our estimation model, GDP is used to proxy for parental work hours or variable $\mathbf{H}$ in Ruhm's model of child outcomes while the health variables, malnutrition and maternal health are proxy variables of child health $\mathbf{C H}$ and parental health, $\mathbf{P H}$ of Contoyannis and Dooley's model. The researchers believe that among the explanatory variables, malnutrition is the only one that negatively affects academic performance, with respect to its impact on educational attainment. A total of six regressions are done, for six different indicators of academic performance of school children in the Philippines.

Based on the analysis of descriptive statistics (see table 1), the model used for this set of regressions will be referred to as Linear Model 2 and has been transformed accordingly:

$A C P=\beta 0-\beta 1 W E I G H T+\beta 2 P R E N A T A L+\beta 3 G D P+\beta 4 \log E X P+u(2)$

Linear Model 2 for the six regressions undertaken is deemed by the researchers to be better, especially in transforming the data on government expenditure. For this regression, the researchers will only include government expenditure on health.

The results of the regressions (See Tables 2-7) show that prevalence of women receiving prenatal care and prevalence of wasting are statistically significant variables with respect to cognitive development and educational attainment, respectively. Wasting is known as low weight-for-age.

This goes to show that prenatal care is by far the most pertinent variable to cognitive development, even though its importance is often overlooked. The window for proper 
prenatal care is limited to the first trimester of pregnancy and is not taken advantage of most of the time for many varying reasons, despite the irreversible effects that it has on a child's cognitive development. Instead, the common occurrence is for people to tend to focus on nourishing the child as he or she grows through feeding him or her proper food.

However in this case, malnutrition was not statistically significant This is explained by the fact that the human brain reaches $80 \%$ of its adult size within the first two years of life. Hence, nutrient supplementation past two years of age has very little effect on the brain's structural and functional development compared to early interventions.

In the case of educational attainment, weight was shown to be statistically significant and had a negative relationship with cohort survival rate. High malnutrition translates to low survival rate in school. This goes to show that malnutrition is one important factor that affects a child's capacity to remain in school, thereby fortifying the importance of schoolbased programs that try to combat severe wasting in children. On the other hand, prenatal care is not significant, which could be explained by how the indicator of academic performance in this regression is not a reflection of cognitive development. While the effects of the absence of prenatal care are irreversible on children and may last well into adulthood, educational attainment in this case has more to do with the present capability of the child to remain in school, an important factor that could gravely affect it being his or her current health status, an equally important component of which is nutrition.

Prior studies looked into individual IQ scores in studying the depreciative effect of malnutrition. IQ testing is the most commonly used tool in assessing general intelligence. The structure and motivation of the general education system is to build and develop skills in different fields of knowledge (i.e. subjects). It is therefore sensible to assess intelligence based on how children perform in a combination of subject areas instead of just limiting the performance evaluation to one subject. This approach to testing several subject areas is also prudent because it gives insight into the condition of the brain as different parts of the brain correspond to different facets of human intelligence. The gross enrollment rate does not capture the impact of the health variables because it does not measure the quality of participation or academic performance. Instead, it only describes the initial commitment to education. As earlier mentioned, the dropout rate is determined by a multitude of factors and the nature of the reason for dropping out may or may not be directly caused by the health variables. More notably, high dropout rates in developing countries are primarily explained by socioeconomic factors. Specifically, the greatest socioeconomic barriers to completing education were found to be high fertility rates and high social tension.

Malnutrition has a negative relationship with cognitive development and educational attainment, as expected. This fortifies the role of nutrition in a child's academic life such that it could either encourage or hamper growth and development, depending on the quality that the child is provided with.

Government expenditure on health represented as logexp proved to be significant to one of the cognitive development indicators. It could be that government expenditure is more closely linked to the capacities that it can provide, such as access to quality prenatal care and adequacy of nutrition-based policies than it is to academic performance. 
Income is less directly related to the dependent variables and more so with the factors that actually allow for the dependent variables to be achieved. For instance, while income may not directly affect a child's cognitive development, it may have an effect on how a mother is afforded access to prenatal care in the first place. Analogously, income might not directly affect a child's educational attainment, but it ultimately determines if he or she has the luxury to even attend school. Additionally, income and prenatal were found to complement each other. This is, however, heavily dependent on the quality of the parents' efforts to effectively hone their children's cognitive ability. A number of studies also have found that "parental commitment to education and parental education levels are important determinants of dropout rates". For instance, high-income families may wish to spend their resources on experiences that they consider to be 'essential' to growth such as vacations, sports, and other recreational activities. Yet, other high-income families could consider books, educational software, and tutoring programs to be essential to growth as well. This example may be used for low-income families as well with slight modifications. Given their limited budget constraint, parents may choose to spend their money on providing enough food for all their children and ensuring they have sufficient allowance or baon for school. On the other hand, parents who strongly regard education to be the greater priority would rather spend on educational investments with the opportunity cost of being sufficiently fed. As an example, even if parents may have sufficient income, it is not guaranteed that they would exhaust this on education. Although parents naturally desire what they deem best for their children, what they decide is best varies per family.

The availability of data may have caused for the lack of significance of many of the explanatory variables with respect to the other dependent variables. In particular, the collection of data for malnutrition and maternal health were not supplied on an annual basis. The researchers utilized the statistic closest to the year with available data, the assumption being that the statistic did not change until the new data was provided. This may have potentially imposed a decreased ability to predict significance among the cognitive development indicators. In order to enhance the regression results, additional regressors that would not pose a problem of multicollinearity with the other explanatory variables could have ideally been used for this study, such as an education variable using average years of schooling as an indicator. However, this data was not available.

The regression analysis confirmed the importance of maternal health and malnutrition as crucial determinants in influencing academic performance. An important byproduct of this analysis was the resulting effects of each explanatory variable in specific areas of academic performance. The findings help dismiss the common misconception of having either malnutrition or poor maternal health to be the greatest impediment to academic performance. Instead, it is possible that these health variables are causative of one another and may lead to a perpetually harmful cycle unless mitigated through proper interventions. As often seen in developing countries, malnutrition already begins in utero. Undernourished mothers often suffer from restricted fetal growth that leads to low infant birth weight. As earlier mentioned in our literature, low infant birth weight results in cognitive developmental delays and a decrease of 4 to 8 points in IQ scores compared to infants with a birth weight that is appropriate-for-gestational-age. The results of our study support earlier research as demonstrated in the regression of the 
Overall National Achievement Test scores. Prenatal health was the most significant determinant of overall NAT scores, which we used as proxy to the standard IQ test. This implies that maternal health interventions and prenatal nutrient supplementation programs aimed to reduce infant malnutrition and its detrimental effects would be most conducive to cognitive development during the 'crucial window of opportunity' that spans from pregnancy to the first two years of age.

Moreover, our study adds to the growing literature illustrating the negative association between high malnutrition and school performance. students who are in a state of hunger cannot give full participation in class. This condition also direly affects their ability to absorb educational material, promote attentiveness, and degrades their social skills with teachers and fellow students.

On the surface, income and health expenditure may appear conducive to honing cognitive development and educational attainment. The results of our study imply that the other variables, namely the economic variables, income and government expenditure in health did not prove to be directly causative to academic performance. A reason for this could be the structure of the relationship between these explanatory variables to our outcome variables. For income, there seems to be a medium between the benefit and the benefactor that takes form in the child's parents. Parents may choose to exhaust their income on what they personally consider to be 'essential' to their child's growth whether it be recreational activities or after-school tutoring programs. On the other hand, government expenditure on education proved to be pertinent to cognitive development and educational attainment, addressing problems such as illiteracy, which was shown to be an important factor in determining quality of motherhood.

Additionally, the nature of some of the data made available for this study greatly limited its scope. For instance, having quality-based data on prenatal care would have added depth to the analysis, however, the unavailability forced the researchers to rely on a quantity-based indicator. As for prevalence of child malnutrition, the researchers were forced to use data per interval, although the researchers deem that having annually updated data would have enriched the analysis as well. For future studies, this should be a consideration especially if availability is still a concern.

\section{Summary and Recommendations}

By utilizing unique independent and dependent variables and making them relevant to the Philippine context, the researchers have updated existing studies and research gaps. For instance, data on the NAT scores and rates pertaining to school retention were not previously used in other studies in conjunction with the health and economic variables chosen for this study. As a result, a new dimension that further defines the boundaries between cognitive development and educational attainment has been introduced. Additionally, the link between child malnutrition and maternal health was repeatedly reinforced.

Recommendations are also necessary for updating research gaps from previous studies, which were not directly addressed by the methodology used in this one. For instance, aside from the Cebu Longitudinal Survey, it is necessary to conduct more longitudinal studies on malnutrition that may help provide a basis for constructing more effective 
policy interventions especially for local government units. These locally or regionally designed policies should take into consideration local agriculture to ensure the policy's viability and properly assess what specific types of vitamin and mineral deficiencies are found in the children in order to target the root causes of malnutrition. Likewise, policy evaluation on existing programs should be conducted on a regular basis. As seen in the examples of the SBFP led by the DepEd and the SMS, policy evaluation allows for the relevant stakeholders involved to identify key areas of improvement and therefore allocate resources more efficiently and target beneficiaries more precisely.

Thus, the researchers also recommend a shift in focus, in terms of policy implementation and formulation, on the importance of maternal health and child malnutrition on the part of the Philippine government. The contents of prenatal care in the country, although generally available and quantifiable, must be better integrated and synthesized so as to be made more easily accessible to the general public. A prenatal care kit, consisting of basic health care services for the first trimester of pregnancy, could be developed by pertinent sectors of the government such as $\mathrm{DOH}$, as part of a program that could seek to provide equitable access to maternal health care across the country.

Apart from this, the government may also choose to focus on improving education on and awareness of the true importance of prenatal care, starting at the barangay level. This government intervention would be relatively easily to implement, given that the services are presently made available and it is only a matter of organizing them more efficiently to benefit a greater number of people. In addressing malnutrition, the government is correct in targeting school children from low-income families through school-based feeding programs. Budget allocation for this particular program should be increased annually in order to make it more sustainable and thereby more effective. If complemented with other programs, such as those that focus on improving instruction and improving the quality of education, this policy could drastically improve not only the health status of its targeted beneficiaries but their overall educational attainment as well.

\section{Appendices}

Table 1: Descriptive Statistics

\begin{tabular}{|c|c|c|c|c|}
\hline Variable & Mean & $\begin{array}{l}\text { Standard } \\
\text { Deviation }\end{array}$ & $\begin{array}{l}\text { Minimum } \\
\text { Value }\end{array}$ & $\begin{array}{l}\text { Maximum } \\
\text { Value }\end{array}$ \\
\hline \multicolumn{5}{|c|}{ DEPENDENT VARIABLES } \\
\hline NAT Overall (\%) & 54.44468 & 6.479123 & 44.94 & 68.88171 \\
\hline NAT Vertal (\%) & 52.0047 & 6.733473 & 43.17 & 67.8092 \\
\hline NAT Math $(\%)$ & 52.45514 & 6.891091 & 44.49 & 69.02959 \\
\hline Cohort Survival Rate (\%) & 72.78 & 4657725 & 63.45 & 79.91 \\
\hline Dropout Rate (\%) & 7.876053 & 1.32371 & 5.99 & 12.51 \\
\hline Gross Enrollment Rate (\%) & 96.00579 & 15.94675 & 73.52 & 119.15 \\
\hline \multicolumn{5}{|c|}{ INDEPENDENT VARLABLES } \\
\hline $\begin{array}{l}\text { Malnutrition prevalence, } \\
\text { weight for age (\%) }\end{array}$ & 23.50526 & 3.557326 & 20.2 & 28.3 \\
\hline $\begin{array}{l}\text { Pregnant women receiving } \\
\text { prenatal care (\%) }\end{array}$ & 88.11579 & 3.791636 & 83.1 & 95.5 \\
\hline Annual GDP Growth (\%) & 4.621248 & 2.03303 & -0.5767222 & 7.632264 \\
\hline $\begin{array}{l}\text { Health expenditure per } \\
\text { capita (USD) }\end{array}$ & 57.5354 & 30.16432 & 28.05091 & 121.5959 \\
\hline $\begin{array}{l}\text { Health expenditure per } \\
\text { capita (Log) }\end{array}$ & 3.930951 & 0.4875227 & 3.334021 & 4.800704 \\
\hline $\begin{array}{l}\text { Experditure on primary and } \\
\text { secondary education (\%) }\end{array}$ & 40.83359 & 16.27839 & 21.80575 & 60.45892 \\
\hline
\end{tabular}


Table 2: NAT $=\beta 0-\beta 1 \mathrm{WEIGHT}+\beta 2$ PRENATAL $+\beta 3$ GDP $+\beta 4 \operatorname{logEXP}+\mathrm{u}$

\begin{tabular}{|c|c|c|c|c|c|c|}
\hline \multicolumn{5}{|c|}{ Linear regression } & $\begin{array}{l}\text { Number of obs } \\
\text { F( 4, 33) } \\
\text { Prob > F } \\
\text { R-squared } \\
\text { Root MSE }\end{array}$ & $\begin{aligned} & =38 \\
& =7.04 \\
= & 0.0003 \\
= & 0.4442 \\
= & 5.1146\end{aligned}$ \\
\hline nat & Coef. & $\begin{array}{l}\text { Robust } \\
\text { Std. Err. }\end{array}$ & $\mathrm{t}$ & $P>|t|$ & [98\% Conf. & Interval] \\
\hline weight & -.281576 & .3562074 & -0.79 & 0.435 & -.8844073 & .3212553 \\
\hline prenatal & .9450063 & .4523456 & 2.09 & 0.044 & .1794746 & 1.710538 \\
\hline gdp & -.0842857 & .598819 & -0.14 & 0.889 & -1.097703 & .9291318 \\
\hline logexp & .0009075 & 2.442162 & 0.00 & 1.000 & -4.132111 & 4.133926 \\
\hline _cons & -21.82084 & 46.25411 & -0.47 & 0.640 & -100.0995 & 56.45779 \\
\hline
\end{tabular}

Table 3: Verbal $=\beta 0-\beta 1 \mathrm{WEIGHT}+\beta 2 \mathrm{PRENATAL}+\beta 3 \mathrm{GDP}+\beta 4 \operatorname{logEXP}+\mathrm{u}$

\begin{tabular}{|c|c|c|c|c|c|c|}
\hline \multicolumn{5}{|c|}{ Linear regression } & $\begin{array}{l}\text { Number of obs } \\
\text { F( 4, 33) } \\
\text { Prob > F } \\
\text { R-squared } \\
\text { Root MSE }\end{array}$ & $\begin{array}{lr}= & 38 \\
= & 7.48 \\
= & 0.0002 \\
= & 0.5134 \\
& =4.9734\end{array}$ \\
\hline verbal & Coef. & $\begin{array}{l}\text { Robust } \\
\text { Std. Err. }\end{array}$ & $t$ & $P>|t|$ & [98s Conf. & Interval] \\
\hline weight & -.1097036 & .3377643 & -0.32 & 0.747 & -.6813224 & .4619153 \\
\hline prenatal & .6885573 & .4070096 & 1.69 & 0.100 & -.0002496 & 1.377364 \\
\hline gdp & .2251629 & .5513622 & 0.41 & 0.686 & -.7079406 & 1.158266 \\
\hline logexp & 3.860028 & 2.534313 & 1.52 & 0.137 & -.4289429 & 8.148999 \\
\hline _cons & -22.30358 & 40.38745 & -0.55 & 0.585 & -90.6537 & 46.04655 \\
\hline
\end{tabular}

Table 4: Math $=\beta 0-\beta 1 \mathrm{WEIGHT}+\beta 2$ PRENATAL $+\beta 3$ GDP $+\beta 4 \operatorname{logEXP}+\mathrm{u}$

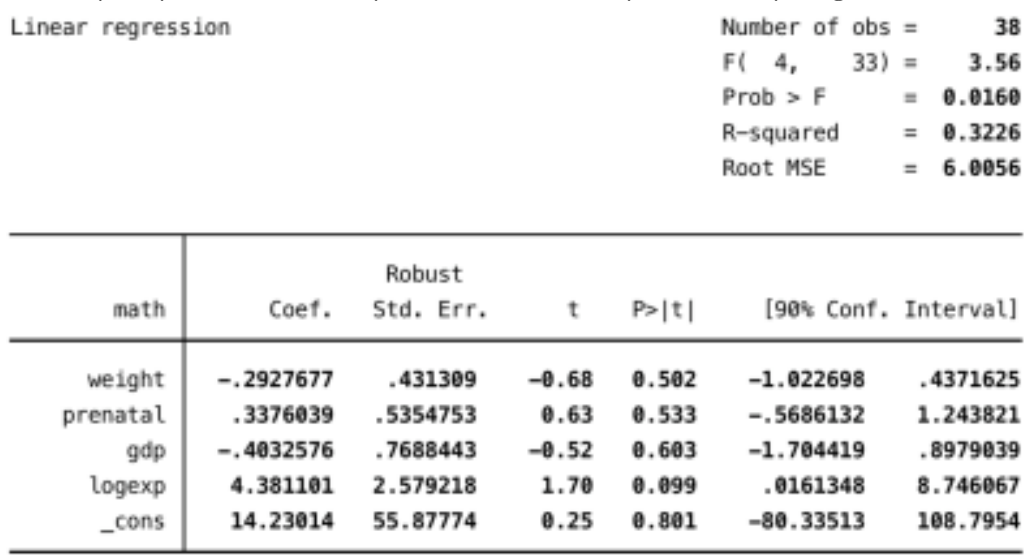

Table 5: CSR $=\beta 0-\beta 1 \mathrm{WEIGHT}+\beta 2 \mathrm{PRENATAL}+\beta 3 \mathrm{GDP}+\beta 4 \log \mathrm{EXP}+\mathrm{u}$ 


\begin{tabular}{r|crc} 
Source & SS & df & MS \\
\hline $\begin{array}{r}\text { Model } \\
\text { Residual }\end{array}$ & $\mathbf{4 1 0 . 0 4 9 9 1}$ & 4 & $\mathbf{1 0 2 . 5 1 2 4 7 8}$ \\
$\mathbf{3 9 2 . 6 4 3 0 9}$ & 33 & $\mathbf{1 1 . 8 9 8 2 7 5 5}$ \\
\hline Total & $\mathbf{8 0 2 . 6 9 3}$ & 37 & $\mathbf{2 1 . 6 9 4 4 0 5 4}$
\end{tabular}

Number of obs $=\quad 38$

$\mathrm{F}(4,33)=8.62$

Prob $>F \quad=0.0001$

R-squared $=0.5108$

Adj $\mathrm{R}$-squared $=0.4516$

Root MSE $=\mathbf{3 . 4 4 9 4}$

\begin{tabular}{r|rrrrrr}
\hline csr & Coef. & Std. Err. & $t$ & $\mathrm{P}>|\mathrm{t}|$ & [96s Conf. Interval] \\
\hline weight & -.7420441 & .2686113 & -2.76 & 0.009 & -1.196631 & -.287457 \\
prenatal & .0904956 & .3348532 & 0.27 & 0.789 & -.4761967 & .6571879 \\
gdp & -.247334 & .3397169 & -0.73 & 0.472 & -.8222574 & .3275894 \\
logexp & 1.577162 & 2.645559 & 0.60 & 0.555 & -2.900077 & 6.054402 \\
_cons & $\mathbf{7 7 . 1 9 1 0 9}$ & 27.22514 & 2.84 & 0.008 & 31.11635 & 123.2658 \\
\hline
\end{tabular}

Table 6: DOR $=\beta 0-\beta 1 \mathrm{WEIGHT}+\beta 2 \mathrm{PRENATAL}+\beta 3 \mathrm{GDP}+\beta 4 \log \mathrm{EXP}+\mathrm{u}$

\begin{tabular}{r|crc} 
Source & SS & df & MS \\
\hline $\begin{array}{r}\text { Model } \\
\text { Residual }\end{array}$ & $\begin{array}{l}8.79244744 \\
56.0392605\end{array}$ & $\begin{array}{r}4 \\
33\end{array}$ & $\mathbf{2 . 1 9 8 1 1 1 8 6}$ \\
\hline Total & 64.8317079 & 37 & 1.75220832
\end{tabular}

Number of obs $=38$

$\mathrm{F}(4,33)=\mathbf{1 . 2 9}$

Prob $>\mathrm{F} \quad=0.2923$

R-squared $\quad=0.1356$

Adj $\mathrm{R}$-squared $=0.0308$

Root MSE $=1.3031$

\begin{tabular}{r|rrrrrr}
\hline dor & Coef. & Std. Err. & $t$ & $P>|t|$ & [908 Conf. Interval] \\
\hline weight & .0541756 & .1014779 & 0.53 & 0.597 & -.1175616 & .2259128 \\
prenatal & -.1339494 & .1265033 & -1.06 & 0.297 & -.3480385 & .0801397 \\
gdp & .0346393 & .1283407 & 0.27 & 0.789 & -.1825594 & .251838 \\
logexp & .3854343 & .9994584 & 0.39 & 0.702 & -1.306009 & 2.076878 \\
_cons & 16.7305 & 10.28531 & 1.63 & 0.113 & -.6759467 & 34.13695 \\
\hline
\end{tabular}

Table 7: GER $=\beta 0-\beta 1 \mathrm{WEIGHT}+\beta 2 \mathrm{PRENATAL}+\beta 3 \mathrm{GDP}+\beta 4 \log \mathrm{EXP}+\mathrm{u}$

\begin{tabular}{r|crc} 
Source & SS & df & MS \\
\hline $\begin{array}{r}\text { Model } \\
\text { Residual }\end{array}$ & $\mathbf{1 0 2 . 5 0 4 2 8 3}$ & $\mathbf{9}$ & $\mathbf{2 5 . 6 2 6 0 7 0 7}$ \\
\hline Total & $\mathbf{9 4 0 9 . 0 6 1 7 3}$ & 37 & $\mathbf{2 5 4 . 2 9 8 9 6 6}$
\end{tabular}

Number of obs $=\quad 38$

$\mathrm{F}(4,33)=0.09$

Prob $>\mathrm{F} \quad=0.9847$

R-squared $\quad=0.0109$

Adj R-squared $=-0.1090$

Root MSE $=16.793$

\begin{tabular}{r|rrrrrr}
\hline ger & Coef. & Std. Err. & $t$ & $\mathrm{P}>|\mathrm{t}|$ & [90\% Conf. Interval] \\
\hline weight & .6210363 & 1.307735 & 0.47 & 0.638 & -1.592123 & 2.834196 \\
prenatal & .6827656 & 1.630234 & 0.42 & 0.678 & -2.076178 & 3.44171 \\
gdp & .2312631 & 1.653913 & 0.14 & 0.890 & -2.567754 & 3.03028 \\
logexp & -.3967816 & 12.87992 & -0.03 & 0.976 & -22.19424 & 21.40068 \\
_cons & 21.73674 & 132.5457 & 0.16 & 0.871 & -202.5784 & 246.0518 \\
\hline
\end{tabular}

(C) 2018 The Authors. Journal Compilation 들 2018 European Center of Sustainable Development. 


\section{References}

Alderman, Harold, Simon Appleton, Lawrence Haddad, Lina Song, and Yisehac Yohannes. Reducing Child Malnutrition: How Far Does Income Growth Take Us? No. DP 01/05. Centre for Research in Economic Development and International Trade, University of Nottingham, 2001.

Begum, Sharifa, and Binayak Sen. "Maternal Health, Child Well-Being and Chronic Poverty: Does Women's Agency Matter?." The Bangladesh Development Studies (2009): 69-93.

Behrman, Jere R., and Nevzer Stacey. The social benefits of education. University of Michigan Press, 1997.

Department of Education, Culture and Sports Research and Statistics Division. DECS Statistical Bulletin School Year 1992-1993. 1993. Raw data. Philippines, Metro Manila.

Department of Education, Culture and Sports Research and Statistics Division. DECS Statistical Bulletin School Year 1993-1994. 1994. Raw data. Philippines, Metro Manila.

Department of Education, Culture and Sports Research and Statistics Division. DECS Statistical Bulletin School Year 1994-1995. 1995. Raw data. Philippines, Metro Manila.

Department of Education, Culture and Sports Research and Statistics Division. DECS Statistical Bulletin School Year 1995-1996. 1996. Raw data. Philippines, Metro Manila.

Department of Education, Culture and Sports Research and Statistics Division. DECS Statistical Bulletin School Year 1996-1997. 1997. Raw data. Philippines, Metro Manila.

Department of Education, Culture and Sports Research and Statistics Division. DECS Statistical Bulletin School Year 1997-1998. 1998. Raw data. Philippines, Metro Manila.

Department of Education, Culture and Sports Research and Statistics Division. DECS Statistical Bulletin School Year 1998-1999. 1999. Raw data. Philippines, Metro Manila.

Department of Education, Culture and Sports Research and Statistics Division. DECS Statistical Bulletin School Year 1999-2000. 2000. Raw data. Philippines, Metro Manila.

Department of Education, Culture and Sports Research and Statistics Division. DECS Statistical Bulletin School Year 2000-2001. 2001. Raw data. Philippines, Metro Manila.

Department of Education Research and Statistics Division. DepEd Statistical Bulletin School Year 20012002. 2002. Raw data. Philippines, Metro Manila.

Department of Education Research and Statistics Division. Indicators 2002-2008. 2016. Raw data. Philippines, Metro Manila.

Department of Education Research and Statistics Division. Basic Education Fact Sheet. 2011. Raw data. Philippines, Metro Manila.

Department of Education Research and Statistics Division. Basic Education Fact Sheet. 2014. Raw data. Philippines, Metro Manila.

Department of Education Bureau of Education Assessment Office. National Achievement Test. Raw data. Philippines, Metro Manila.

DEPED. "DO 91, S. 2009 Prescribing Guidelines and Requirements Regulating the Use of National Examination Results." DO 91, S. 2009. Department of Education Philippines, 2 Sept. 2009. Web.

DOH. "Women's Health and Safe Motherhood Project." Department of Health Philippines, n.d. Web.

Gigante, D. P., et al. "Epidemiology of early and late growth in height, leg and trunk length: findings from a birth cohort of Brazilian males." European journal of clinical nutrition 63.3 (2009): 375-381.

Grossman, Michael. The buman capital model of the demand for health. No. w7078. National Bureau of Economic Research, 1999.

Jefferis, Barbara JMH, Chris Power, and Clyde Hertzman. "Birth weight, childhood socioeconomic environment, and cognitive development in the 1958 British birth cohort study." Bmj 325.7359 (2002): 305.

Kes, Aslihan, et al. "The economic burden of maternal mortality on households: evidence from three subcounties in rural western Kenya."Reprod Health 12.suppl 1 (2015): S3.

Lavado, Rouselle F., and Leizel P. Lagrada. Are maternal and child care programs reaching the poorest regions in the Philippines?. No. DP 2008-30. Philippine Institute for Development Studies, 2008.

Lavado, Rouselle F., Leizel P. Lagrada, Valerie Gilbert T. Ulep, and Lester M. Tan. Who Provides Good Quality Prenatal Care in the Pbilippines?. No. DP 2010-18. Philippine Institute for Development Studies, 2010. 
Léger, Pierre. "Graduate Health Economics: Background, Theory and Practice." (2013): n.d. Web. 15 Feb. 2016.

Nyaradi, Anett, et al. "The role of nutrition in children's neurocognitive development, from pregnancy through childhood." (2013).

Official Gazette. "Republic Act No. 10354." Republic of the Philippines. GOVPH, 12 Dec. 2012. Web. 4 Mar. 2016.

Ruhm, Christopher J. "Parental employment and child cognitive development." Journal of Human Resources 39.1 (2004): 155-192.

Sachdev, Harshpal S., et al. "Anthropometric indicators of body composition in young adults: relation to size at birth and serial measurements of body mass index in childhood in the New Delhi birth cohort." The American journal of clinical nutrition 82.2 (2005): 456-466.

Save the Children. "Sizing Up: The Stunting and Child Malnutrition Problem in the Philippines." (2015): n. pag. 2015. Web.

Stewart, M. Kathryn, Cynthia K. Stanton, Mario Festin, and Nora Jacobson. "Issues in Measuring Maternal Morbidity: Lessons from the Philippines Safe Motherhood Survey Project." Studies in Family Planning 27.1 (1996): 29. Web.

Tabunda, Ana Maria L., Jose Ramon G. Albert, and Imelda Angeles-Agdeppa. Results of an Impact Evaluation Study on DepED's School-Based Feeding Program. No. DP 2016-05. Philippine Institute for Development Studies, 2016.

UNFPA. "Will Philippine Women Continue to Die During Childbirth?" United Nations Population Fund Philippines. N.p., n.d. Web.

UNICEF. "Maternal and Newborn Health Country Profiles: Philippines." SpringerReference (n.d.): n. pag. UNICEF. Web.

USAID. "Maternal and Child Health Integrated Program Philippines." Maternal and child health integrated program (MCHIP) - Philippines. N.p., n.d. Web. 09 Apr. 2016.

The World Bank DataBank. GDP growth (annual \%). N.d. Raw data. N.p.

The World Bank DataBank. Health expenditure per capita (current US\$). N.d. Raw data. N.p.

The World Bank DataBank. Pregnant women receiving prenatal care (\%). N.d. Raw data. N.p.

The World Bank DataBank. Prevalence of underweight, weight for age (\% of children under 5). N.d. Raw data. N.p.

The World Bank. "Repositioning Nutrition as Central to Development." (2005): n. pag. 2007. Web.

Victora, Cesar G et al. "Maternal and Child Undernutrition: Consequences for Adult Health and Human Capital." Lancet 371.9609 (2008): 340-357. PMC. Web. 